\title{
Sobre un caso de torsión e infarto hemorrágico del anexo derecho
}

\section{Doctor Alberto Gómez Tamayo}

Paciente N. N., de 18 años, soltera, que fue vista por primera vez el 6 de octubre de 1956 por "dolor abdominal", localizado especialmente en F. I. D., y de 36 horas de duración, había coincidido con la iniciación de la menstruación el día anterior, no había cedido con analgésicos de tipo aspirina y había sido interpretado como un cólico menstrual.

Como antecedentes personales habian: de tipo congénito una Dextrocardia (comprobada por rayos $\mathrm{X}$ ), Escoliosis lumbar, una falta de desarrollo del seno derecho, siendo en tamaño casi la mitad que el del lado opuesto y ausencia del vello axilar derecho, siendo normal en el lado izquierdo. Había también una implantación del ano anterior a donde debía encontrarse normalmente hallándose el ano a 2 centímetros del introito vaginal.

La paciente había sido sometida a apendicectomía hacía catorce años.

La revisión de sistemas dio como resultado el que no habia habído evacuación intestinal ni expulsión de gases desde el día anterior.

Al examen se encontró una paciente bien nutrida que se quejaba de dolor en la F. I. D., el pulso era de 75, T. A. de $10 \times 6$, el examen general era negativo a excepción de defensa y de dolor provocado a la palpación sobre el sitio de cicatriz de la apendicectomía. 
En estas condiciones pasaron doce horas en que recibió a.trinal y Demerol, una placa simple de abdomen fue negativa para asas dilatadas o niveles líquidos; el cuadro hemático cio: Glóbulos rojos, 4.800.000; Hemoglobina, 14\%; Glóbulos blancos, 17.700; T. de sedimentación, $50 \mathrm{~ms}$. a la hora; el examen parcial de orina mostró cilindruria únicamente como dato positivo anormal; así continuó por diez horas más, el cuadro no cecía, el estado general era bastante satisfactorio.

Un tacto rectal dio como resultado la sensación de masa fluctuante en el fondo de Douglas muy doloroso y fijo.

Con el diagnóstico de impresión de torsión de quiste ovárico se practicó una laparatomía media infraumbilical y se encontró: asas intestinales congestionadas y muy poco distendidas; la trompa derecha convertida en una masa roja, redondeada de 18 x 8 centímetros, torsionada una y media vez y que ocupaba el Douglas, Utero y anexos del otro lado sanos.

Se practicó una anexectomía derecha en la usual manera con peritonización posterior. El diagnóstico post-operatorio fue por lo tanto infarto y torsión del anexo derecho con fenómenos de ileus paralítico reflejo.

El post-operatorio evolucionó sin complicaciones y al sexto cía la paciente salió de la clínica.

El reporte anatomo-patológico dio el siguiente resultado:

Pieza: anexo derecho. Sexo femenino. Edad: dieciocho años. Fistado civil: soltera.

\section{Descripción macroscópica}

La pieza consiste en un anexo muy aumentado de tamaño con la forma de retorta que mide 18 centímetros de longitud y 8 centímetros de diámetro en su parte más ancha. Es de color vino tinto por extensa infartación hemorrágica y es fluctuante. Las franjas están evertidas, aumentadas de tamaño y de color rojo negruzco por la misma infartación hemorrágica. La serosa es generalmente brillante, pero muestra algunos depósitos fibrinosos. Al corte de la masa quística escapa líquido acuoso teñido por sangre, no filante. Se puede sondear con facilidad la trompa cuyos pliegues mucosos están hipertrofiados por la infartación hemorrágica. La luz tubo-ovárica no está 
en comunicación con el quiste, cuya superficie interior muestra en un sitio pequeñas excrecencias papilares no mayores de 0.1 centímetro. El resto es liso y como la superficie exterior, extensamente infartado por sangre. Aunque no es posible reconocer tejido ovárico, el aspecto y el sitio de la lesión justifican el diagnóstico de un adenoma quístico papilar del ovario.

\section{Descripción microscópica}

Los cortes permiten reconocer oviductos extensamente infartados por sangre y con epitelio totalmente desnutrido. Cortes del quiste muestran tejido conjuntivo igualmente infartado en cuya superficie interior se implantan vegetaciones papilares constituídas por tejidos fibrosos densos cuyo epitelio también está desnutrido por necrosis. No hay evidencia de malignidad.

DIAGNOSTICO: Torsión e infarta hemorrágico del anexo derecho con adenoma quístico papilar seroso ovárico.

Firmado: doctor Egon Lichtenberger 